\title{
Reconstructing ice-age climates: quantifying low-CO2 effects on plants
}

\section{Article}

\section{Accepted Version}

Creative Commons: Attribution-Noncommercial-No Derivative Works 4.0

Prentice, I. C., Cleator, S. F., Huang, Y. H., Harrison, S. P. and Roulstone, I. (2017) Reconstructing ice-age climates: quantifying low-CO2 effects on plants. Global and Planetary Change, 149. pp. 166-176. ISSN 0921-8181 doi: https://doi.org/10.1016/j.gloplacha.2016.12.012 Available at https://centaur.reading.ac.uk/68643/

It is advisable to refer to the publisher's version if you intend to cite from the work. See Guidance on citing.

To link to this article DOI: http://dx.doi.org/10.1016/j.gloplacha.2016.12.012 Publisher: Elsevier

All outputs in CentAUR are protected by Intellectual Property Rights law, including copyright law. Copyright and IPR is retained by the creators or other copyright holders. Terms and conditions for use of this material are defined in the End User Agreement.

\section{www.reading.ac.uk/centaur}

\section{CentAUR}

Central Archive at the University of Reading 
Reading's research outputs online 


\title{
Reconstructing ice-age palaeoclimates: quantifying low- $\mathrm{CO}_{2}$ effects on plants
}

\author{
Prentice, I.C. ${ }^{\mathrm{a}, \mathrm{b}}$, Cleator, S.F. ${ }^{\mathrm{c}}$, Huang, Y.H. ${ }^{\mathrm{c}}$, Harrison, S.P. ${ }^{\mathrm{b}, \mathrm{d}}$, Roulstone, I. $^{\mathrm{c}}$ \\ ${ }^{a}$ AXA Chair of Biosphere and Climate Impacts, Department of Life Sciences, Imperial College London, Silwood Park Campus, \\ Buckhurst Road, Ascot SL5 YPY, UK \\ ${ }^{b}$ Department of Biological Sciences, Macquarie University, North Ryde, NSW 2109, Australia \\ ${ }^{c}$ Department of Mathematics, University of Surrey, Guildford GU2 7XH, UK \\ ${ }^{d}$ School of Archaeology, Geography and Environmental Sciences (SAGES), University of Reading, Whiteknights, Reading RG6 6AH, \\ $U K$
}

Corresponding author: Iain Colin Prentice

AXA Chair of Biosphere and Climate Impacts, Department of Life Sciences

Imperial College London, Silwood Park Campus, Buckhurst Road

Ascot SL5 7PY, UK

iain.colin.prentice@gmail.com

Preprint accepted for publication in Global and Panetary Change 


\begin{abstract}
We present a novel method to quantify the ecophysiological effects of changes in $\mathrm{CO}_{2}$ concentration during the reconstruction of climate changes from fossil pollen assemblages. The method does not depend on any particular vegetation model. Instead, it makes use of general equations from ecophysiology and hydrology that link moisture index (MI) to transpiration and the ratio of leaf-internal to ambient $\mathrm{CO}_{2}(\chi)$. Statistically reconstructed MI values are corrected post facto for effects of $\mathrm{CO}_{2}$ concentration. The correction is based on the principle that $e$, the rate of water loss per unit carbon gain, should be inversely related to effective moisture availability as sensed by plants. The method involves solving a non-linear equation that relates $e$ to $\mathrm{MI}$, temperature and $\mathrm{CO}_{2}$ concentration via the Fu-Zhang relation between evapotranspiration and MI, Monteith's empirical relationship between vapour pressure deficit and evapotranspiration, and recently developed theory that predicts the response of $\chi$ to vapour pressure deficit and temperature. The solution to this equation provides a correction term for MI. The numerical value of the correction depends on the reconstructed MI. It is slightly sensitive to temperature, but primarily sensitive to $\mathrm{CO}_{2}$ concentration. Under low $\mathrm{LGM} \mathrm{CO}_{2}$ concentration the correction is always positive, implying that LGM climate was wetter than it would seem from vegetation composition. A statistical reconstruction of last glacial maximum (LGM, 21 $\pm 1 \mathrm{kyr} \mathrm{BP}$ ) palaeoclimates, based on a new compilation of modern and LGM pollen assemblage data from Australia, is used to illustrate the method in practice. Applying the correction brings pollen-reconstructed LGM moisture availability in southeastern Australia better into line with palaeohydrological estimates of LGM climate.
\end{abstract}

Keywords: Last Glacial Maximum, palaeoclimate reconstruction, moisture index, water-use efficiency, plant available moisture

\title{
1. Introduction
}

Atmospheric $\mathrm{CO}_{2}$ concentration, $\left[\mathrm{CO}_{2}\right]$, has a direct effect on plant physiological processes that is distinct from the effects of climate change. Increasing $\left[\mathrm{CO}_{2}\right]$ allows plants that use the standard $\mathrm{C}_{3}$ pathway of photosynthesis (including most crops, temperate grasses and forbs, and nearly all trees) to assimilate more carbon while losing less water, implying an increase in water use efficiency or, equivalently, a reduction in $e$, the water lost by transpiration per unit carbon fixed by photosynthesis. Increasing $\left[\mathrm{CO}_{2}\right]$ today is reducing $e$, as can be shown directly by comparing $\mathrm{CO}_{2}$ and latent heat fluxes, or indirectly from stable carbon isotope discrimination $\left(\Delta^{13} C\right)$ measured in tree rings (Keenan et al., 2013; Dekker et al., 2016). $\Delta^{13} C$ provides a quantitative indication of the ratio $(\chi)$ of leaf-internal to ambient $\left[\mathrm{CO}_{2}\right]$. Theory and laboratory studies (e.g. Dewar, 1997; Ward et al., 2005; Ainsworth and Rogers, 2007; Gerhart et al., 2012; Prentice et al., 2014; Wang et al., 2016) indicate that $\chi$ is conservative with respect to changes in ambient $\left[\mathrm{CO}_{2}\right]$. Therefore, leaf-internal $\left[\mathrm{CO}_{2}\right]\left(c_{i}\right)$ increases with increasing ambient $\left[\mathrm{CO}_{2}\right]\left(c_{a}\right)$. The rate of carbon assimilation increases with $c_{i}$, but at a diminishing rate, resulting in partial stomatal closure - as required to keep $\chi$ constant. Thus carbon assimilation increases while water loss decreases, both effects causing a reduction in $e$. Consequences of declining $e$ in $\mathrm{C}_{3}$ plants today include observable greening in warm, semi-arid regions of the world (Donohue et al., 2013; Ukkola et al., 2015) and woody thickening (shift from grass- to tree-dominance) in mixed tree-grass ecosystems (Bond et al., 2003; Kgope et al., 2010).

Given the significance of $\left[\mathrm{CO}_{2}\right]$ for plants and vegetation, effects of low $\left[\mathrm{CO}_{2}\right]$ should be considered when interpreting vegetation of the past, including glacial maxima when $\left[\mathrm{CO}_{2}\right]$ was low (Farquhar, 1997; Prentice and Harrison, 2009; Gerhart and Ward, 2010; Bragg et al., 2013 and references therein). The contrary view of Huang et al., 2001, although widely cited, appears to rest on the misconception that climate and $\mathrm{CO}_{2}$ effects are mutually exclusive explanations for vegetation changes (see the discussion in Bragg et al., 2013). Vegetation changes from the last glacial maximum (LGM, $21 \pm 1 \mathrm{kyr} \mathrm{BP}$ ) to the present (Holocene) interglacial include a major shift from $\mathrm{C}_{4}$ to $\mathrm{C}_{3}$ plant dominance in tropical Africa, and a worldwide increase in forest cover. These changes cannot be explained by climate change alone, but they become predictable by process-based models when $\left[\mathrm{CO}_{2}\right]$ effects are considered in addition to those of climate (Harrison and Prentice, 2003; Bragg et al., 2013; Martin Calvo and Prentice, 2015).

Current standard modern-analogue methods to reconstruct past temperature and moisture regimes from pollen or plant macrofossil data do not take $\mathrm{CO}_{2}$ effects into account, although several studies have shown that these effects are important (e.g. Jolly and Haxeltine, 1997; Cowling and Sykes, 1999) and have pointed out that the failure to account for these effects may help to explain discrepancies between observed and simulated climates (e.g. Harrison and Prentice, 2003; Ramstein et al., 2007). One possible approach, based on the inversion of process-based vegetation models, has shown significant effects on LGM palaeoclimate reconstructions when changes in $\left[\mathrm{CO}_{2}\right]$ are imposed (e.g. Guiot et al., 2000; Wu et al., 2007). The success of the model inversion approach depends on the 
correctness of a particular (complex) model. The structure of existing process-based vegetation models includes discontinuities caused inter alia by climatic limits of different plant functional types; these could potentially cause artefacts in the form of discontinuities in reconstructed climate variables. Results are likely to be model-dependent, leading to an unquantified structural uncertainty in the reconstructions. These are significant drawbacks, which have probably limited the wider use of the model inversion approach.

Here we describe a prototype of a more general and analytically tractable method. It is an extension of the simple post facto correction approach that Wang et al., 2013 used to estimate the effects of projected future $\left[\mathrm{CO}_{2}\right]$ increases on vegetation patterns, as simulated in that study by a statistical model. The idea behind our new method is that climate changes are reconstructed statistically first (using any suitable method), then a correction term is added to the reconstructed values of the moisture variable (here Moisture Index, MI defined as the ratio $P / E_{q}$ where $P$ is mean annual precipitation and $E_{q}$ is mean annual equilibrium evapotranspiration: see e.g. Prentice et al., 2011). The correction term $(\Delta m)$ allows for the fact that under low $\left[\mathrm{CO}_{2}\right]$ vegetation appears dry due to the higher plant demand for water (increased $e$ ) at low $\left[\mathrm{CO}_{2}\right]$. We introduce a set of equations to describe the controls on $e$, and derive a computationally efficient method to solve the coupled equation system for $\Delta m$. We show how $\Delta m$ depends on the reconstructed value of MI, modern and reconstructed temperatures, and $\left[\mathrm{CO}_{2}\right]$. We then apply the method to a statistically based reconstruction of LGM climates in Australia. The restriction to Australia allows us to ignore some complications that would need to be tackled in a global analysis. These include the influence of large elevation differences on various non-climate parameters (such as the partial pressure of $\mathrm{O}_{2}$ on the affinity of Rubisco for $\mathrm{CO}_{2}$ ) that influence plant carbon uptake and water loss, and the decoupling of summer and winter temperatures that characterizes the northern continents and would require the seasonal cycle to be treated explicitly. For simplicity, we consider only mean annual values of climate variables, and do not consider the possibility of seasonally differentiated climate changes between LGM and recent times.

\section{Methods}

\subsection{Model}

Fig.1 summarizes the web of influences of climate and $\left[\mathrm{CO}_{2}\right]$ on $e$. The climate variables to be reconstructed from pollen data (see Bartlein et al., 2011 for a global overview of pollen-based climate reconstructions) are assumed to be mean annual temperature $(T)$ and MI $(m)$. We consider each intermediate variable in turn, and specify general equations to represent the controls on each variable as shown by the arrows in Fig.1. Many approximations are involved, but they are all explicit, and their consequences testable.

\subsubsection{Moisture index, net radiation and evapotranspiration}

By the definition of MI,

$$
m=\frac{P}{E_{q}}
$$

where $E_{q}$ represents the equilibrium evapotranspiration, i.e. the theoretical rate of evaporation from a well-watered vegetation surface under steady-state conditions (see e.g. Huntingford and Monteith, 1998). $E_{q}$ is an increasing function of net radiation and temperature:

$$
\lambda E_{q}=R_{n}\left[\frac{s}{s+\gamma}\right]
$$

where $\lambda$ is the latent heat of vaporization of water $\left(2.45 \mathrm{MJ} \mathrm{kg}^{-1}\right), R_{n}$ is the annual net radiation at the vegetated surface $\left(\mathrm{MJ} \mathrm{m}^{-2}\right), \gamma$ is the psychrometer constant $\left(0.067 \mathrm{kPa} \mathrm{K}^{-1}\right.$ at sea level), and $s\left(\mathrm{kPa} \mathrm{K}^{-1}\right)$ is $\frac{\partial e_{s}}{\partial T}$ where $e_{s}$ is the saturated vapour pressure of water $(k P a)$. The term $s$ is closely approximated by the Roche-Magnus formula (Allen et al., 1998):

$$
e_{s}=0.6108 \exp \left[\frac{17.27 T}{237.3+T}\right]
$$

where $T$ is Celsius temperature $\left({ }^{\circ} \mathrm{C}\right) . R_{n}$ is the balance of net incoming shortwave and net outgoing longwave radiation, approximated here by (Linacre, 1968):

$$
R_{n}=0.83 R_{0}\left(0.25+0.5 S_{f}\right)-(107-T)\left(0.2+0.8 S_{f}\right)
$$

where $R_{0}$ is the incident solar radiation at the top of the atmosphere (insolation) and $S_{f}$ is the fraction of possible sunshine hours (approximately the one-complement of cloud cover fraction). Annual insolation is a function of latitude and the Earth's axial obliquity, and was only marginally $(\approx 0.1 \%)$ different at the LGM at the latitude of 
Australia; we ignore this difference. The influence of $S_{f}$ on $R_{n}$ is large, however and cannot be ignored even if we generally lack direct evidence for changes in $S_{f}$. Strong empirical relationships between mean annual values of $S_{f}$ and $m$ (as shown in Fig.10) allow us to estimate $S_{f}$. We used climate data for the interval from $1970-1999$ (M. Hutchinson, pers.comm.) to fit the following relationship by non-linear regression:

$$
S_{f}=0.6611 e^{-0.74 m}+0.2175 .
$$

Area-averaged actual evapotranspiration $\left(E_{a}\right)$ is a compromise between the energy-limited rate in wet climates, and the water-limited rate in dry climates, with a smooth transition between these limits. This behaviour is encapsulated in the Budyko curve. The Fu-Zhang form of this curve provides a relationship between $E_{a}$ and $m$ (Zhang et al., 2004):

$$
E_{a}=E_{q}\left[1+m-\left(1+m^{\omega}\right)^{\frac{1}{\omega}}\right]
$$

where $\omega \approx 3$. We disregard variation around this canonical value.

\subsubsection{Plant water use, $\mathrm{CO}_{2}$ drawdown and the atmospheric moisture deficit}

The $\mathrm{CO}_{2}$ drawdown, or the ratio between leaf-internal $\left(c_{i}\right)$ and ambient $\left(c_{a}\right)\left[\mathrm{CO}_{2}\right]$ (symbolized here by $\chi$ ), is an index of the regulation of water vapour loss through stomata. The proximal driver of water vapour loss at the leaf scale is the vapour pressure deficit, $D$ (the difference between $e_{a}$, the actual water vapour pressure, and $e_{s}$ ). We use the cumulative atmospheric moisture deficit $\Delta E$ (the difference between $E_{q}$ and $E_{a}$ ) as a surrogate for $D$. Prentice et al., 2014 showed how optimal values of $\chi$ (which minimize total costs of maintaining the biochemical capacity for photosynthesis and the capacity for water transport) can be predicted from $T$ and $\Delta E$. The Appendix in Prentice et al. (2014) shows that $\Delta E$ is related to $D$ by a scaling constant $g_{0}$, following the empirical model for $E_{a}$ by Monteith, 1995 (later derived theoretically by Huntingford and Monteith, 1998). Optimal $\chi$ is then approximated by (Wang et al., 2014):

$$
\chi=\left[1+C\left(\frac{\eta}{K}\right)^{\frac{1}{2}} \Delta E^{\frac{1}{4}}\right]^{-1}
$$

where $\eta$ is the viscosity of water $(\mathrm{mPa} \mathrm{s}) ; K$ is the effective Michaelis-Menten coefficient for carboxylation $(\mu \mathrm{mol}$ $\mathrm{mol}^{-1}$ ); and $C$ is an empirical constant (14.76, when $\Delta E$ is in $\mathrm{mm}$ ). The value of $C$ was chosen so as to give a realistic value of $\chi$ under warm-temperate, humid conditions (Wang et al., 2014). Both $\eta$ and $K$ are functions of absolute temperature $T_{K}(K)$ :

$$
\eta=0.024258 \exp \left[\frac{580}{T_{K}-183}\right]
$$

(Vogel, 1921) and

$$
K=K_{C}\left(1+\frac{O}{K_{O}}\right)
$$

(Farquhar et al., 1980) where

$$
K_{C}=404.9 \exp \left[\frac{\Delta H_{C}}{R}\left(\frac{1}{298}-\frac{1}{T_{K}}\right)\right]\left(\mu \mathrm{mol} \mathrm{mol}^{-1}\right)
$$

and

$$
K_{O}=278.4 \exp \left[\left(\frac{\Delta H_{O}}{R}\right)\left(\frac{1}{298}-\frac{1}{T_{K}}\right)\right](\% 0)
$$

(Bernacchi et al., 2001). Here the $\Delta H$ are activation energies $\left(79430 \mathrm{~J} \mathrm{~mol}^{-1}\right.$ for $K_{C}$ and $36380 \mathrm{~J} \mathrm{~mol}^{-1}$ for $K_{O}$ ) (Bernacchi et al., 2001), $R$ is the universal gas constant $\left(8.314 \mathrm{~J} \mathrm{~mol}^{-1} \mathrm{~K}^{-1}\right.$ ) and $O$ is the atmospheric concentration of oxygen $(210 \%)$.

Plant water use can be quantified using Fick's law, which applies to both water lost and $\mathrm{CO}_{2}$ gained by diffusion through the stomata. $\mathrm{CO}_{2}$ uptake $(A)$ is given by:

$$
A=g_{s} c_{a}(1-\chi)
$$

where $g_{s}$ is the surface conductance (dependent on leaf area and stomatal conductance). Water loss by transpiration $(E)$ is given by:

$$
E=1.6 g_{s} D
$$


The factor 1.6 arises because water, as a smaller molecule, diffuses more readily than $\mathrm{CO}_{2}$. The ratio $E / A$ is then given by:

$$
e=1.6 \frac{D}{c_{a}(1-\chi)}
$$

which is, conveniently, independent of $g_{s}$. Equation (2.14) expresses the fact that water loss is proportional to vapour pressure deficit, while $\mathrm{CO}_{2}$ gain is proportional to ambient $\left[\mathrm{CO}_{2}\right]$. It also shows how both are regulated by $\chi$, which is a conservative quantity that nonetheless consistently declines with increasing $D$; thus partially counteracting the effect of vapour pressure deficit on water loss.

\subsection{Pollen Base Climate Reconstruction Method}

The pollen data set is an updated version of the Australasian pollen data set originally developed for the BIOME 6000 project (Pickett et al., 2004; Herbert and Harrison, 2016). We follow the convention of defining the modern period as the interval < $500 \mathrm{yr}$ BP, and the Last Glacial Maximum (LGM) as between 22,000 and 20,000 yr BP (Bartlein et al., 2011). The modern data set (Herbert and Harrison, 2016) has 1464 surface and core-top samples dated to $<500$ yr BP from 321 sites (SI Table 1). The LGM data set contains 52 samples from 27 sites (SI Table 2).

Most pollen taxa were generally identified to genus level in the original data sets, but some were only assigned to broad palynological types or even families. Some rarer and not necessary taxonomically-related types were grouped together. In order to overcome the differences in taxonomic resolution between different records, the pollen taxa were allocated to 25 plant functional types (PFTs) on the basis of information on life form, leaf form, phenology and climatic range (SI Table 3). Some pollen taxa were necessarily assigned to multiple PFTs (SI Table 4). Pollen taxa likely to represent local conditions (i.e. aquatic taxa, mangroves, parasitic plants, mosses) or anthropogenic disturbance of the natural vegetation (i.e. agricultural crops, introduced species) were removed from the pollen data set prior to analysis and are therefore not included in SI Table 4.

Of the 903 taxa represented in either the modern or LGM data sets, only $63 \%$ are allocated to a unique PFT. This problem is partly caused by the large number of identifications to only families or sub-families ( $15 \%$ of the taxa); $70 \%$ of the families represented in the data set can include representatives of multiple PFTs. However, the Australian flora is characterised by a large number of genera of high diversity and broad climatic ranges. The classic case is Eucalyptus, with more than 700 species including trees and shrubs, and occupying almost all extant climatic niches across the continent. Although attempts have been made to distinguish broad ecological groups of Eucalyptus from their pollen morphology (see e.g. Pickett and Newsome, 1997), this practice is not widespread. Other genera in our dataset which are generally not distinguished to species level in Australian pollen records and which represent multiple PFTs include e.g. Acacia (7 PFTs), Melaleuca (5 PFTs), Dodonea (5 PFTs), Euphorbia (7 PFTs).

One way of reducing the ambiguity of PFT allocations is to use information on the occurrence of other PFTs in the sample. For example, the presence of obligate tropical taxa in a sample makes it likely that taxa that have a wider climatic range were, in reality, also tropical. Similarly, the presence of forest taxa in a sample makes it likely that taxa that could occur as trees in forests or as shrubs in open vegetation were, in reality, trees. PFTs were assigned an index for cold temperature tolerance $\left(V_{T}\right)$ and for the degree of openness of the vegetation $\left(V_{C}\right)$ in which they occur (SI Table 5). The distribution of some PFTs is unaffected by low temperature limits and these were not assigned a value for $V_{T}$. Initial values of $V_{T}$ and $V_{C}$ were calculated for each sample based on the original allocation of taxa to PFTs, including to multiple PFTs. Weights were then recalculated for each PFT in the sample based on the likelihood that it was present given the value of $V_{T}$ and $V_{C}$ in the sample compared to the values for the individual PFTs. The general form of the Gaussian is given by:

$$
f(x)=\frac{1}{2} \pi \sigma^{2} e^{-d^{2} 2 \sigma^{2}}
$$

where $d$ is the difference (in our case, between the $V_{T}$ or $V_{C}$ value of the PFT and the current $V_{T}$ or $V_{C}$ value of the sample) and $\sigma$ is the standard deviation, which is a measure of the "window width" (set to 1 in this case). New weights were derived by multiplying these weights by the weights obtained for the original assignment. This procedure was iterated twice to yield a set of 'PFT scores' for each sample.

PFT scores were normalized to sum to 1 for each sample, then (following Wang et al., 2013) we fitted a GLM with logit link function and assumed binomial distribution of residuals (i.e. multiple logistic regression) using a linear predictor composed of the climate variables and their squares; this approach fits independent unimodal response functions for each variable. We used climate data for the interval from $1970-1999$, interpolated using the ANUSPLIN thin-plate spline fitting package (Hutchinson, 2004) to interpolate the meteorological data to a $0.05^{\circ}$ 
grid cell resolution climatology (M. Hutchinson, pers.comm.). These data are now available from ANUClimate grids (http://www.emast.org.au/our-infrastructure/models/anuclimate-1-0-2/). The RMSE of the $T$ reconstructions for the modern samples is $1.97^{\circ} \mathrm{C}$, while the reconstructions of MI have a RMSE of 0.23 . Palaeoclimate estimates were obtained for each fossil pollen spectrum by maximum likelihood, based on the fitted model.

\subsection{Estimation of the correction term: principle}

Our goal was to estimate a term $\Delta m$ such that $m_{t}=m_{r e c}+\Delta m$, where $m_{t}$ approximates the true MI for an LGM sample, and $m_{r e c}$ is the statistically reconstructed value for that sample. This term should satisfy the following equality:

$$
e\left(T_{r e c}, m_{t}, c_{a}\right)=e\left(T_{m}, m_{r e c}, c_{a m}\right)
$$

where $e$ is now expressed as a function of temperature, MI and $\left[\mathrm{CO}_{2}\right]$ in that order; $T_{r e c}$ is the statistically reconstructed annual mean temperature for a given time and location; $c_{a}$ is the $\left[\mathrm{CO}_{2}\right]$ at that time; $T_{m}$ is the modern annual mean temperature at that location; and $c_{a m}$ is the modern $\left[\mathrm{CO}_{2}\right]$. We assume that $T_{r e c}$ is correct, and not biased by $\mathrm{CO}_{2}$ effects. Equation (2.16) states that the true MI under low $\left[\mathrm{CO}_{2}\right]$, at the palaeotemperature, should be the value for which the plant water loss per unit carbon gain is equal to that corresponding to the apparent (reconstructed) MI under modern $\left[\mathrm{CO}_{2}\right]$ at the modern temperature. This statement assumes that the degree of water stress to which plants are subject (and to which different plant types are differentially adapted) is quantified by $e$, that is, the rate at which the plant has to lose water in order to gain carbon.

\subsection{The $\mathrm{CO}_{2}$ compensation point as a constraint}

$\mathrm{C}_{3}$ photosynthesis requires at least that

$$
c_{i}>\Gamma^{*}
$$

where $\Gamma^{*}$ is the photorespiratory compensation point, that is the leaf-internal $\left[\mathrm{CO}_{2}\right]$ at which $\mathrm{CO}_{2}$ uptake (even in the absence of mitochondrial respiration) would be zero. $\Gamma^{*}$ increases with temperature as follows:

$$
\Gamma^{*}=42.75 \exp \left[\frac{\Delta H_{\Gamma}}{R}\left(\frac{1}{298}-\frac{1}{T_{K}}\right)\right]\left(\mu \mathrm{mol} \mathrm{mol}^{-1}\right)
$$

where $\Delta H_{\Gamma}=37830 \mathrm{~J} \mathrm{~mol}^{-1}$ (Bernacchi et al., 2001). This requirement imposes a constraint. It implies that the range of environments that are too dry for $\mathrm{C}_{3}$ plants to survive, other things being equal, is extended under low $\left[\mathrm{CO}_{2}\right]$. However, the temperature dependence implies that reduced ice-age temperatures (a climatic consequence of low $\left[\mathrm{CO}_{2}\right]$ ) mitigated this effect (Cowling and Shin, 2006; Martin Calvo and Prentice, 2015). Taking dark respiration into account, the $\mathrm{CO}_{2}$ compensation point is closely approximated by $\Gamma^{*}+b K$ where $b \approx 0.025$ (Prentice et al., 2014). Here we use the requirement that $c_{i}>\Gamma^{*}+0.025 K$ to limit the range of allowable values for $m_{t}$.

\subsection{Estimation of the correction term: solution}

Equation (2.16) has no analytical solution. SI Appendix A describes a method developed here to solve it efficiently through an algebraic simplification of the equation system represented by equations (2.1)-(2.16). The equation to be solved is ultimately expressed as:

$$
F\left(m_{t}\right)=\left(u e^{-0.74 m}+v\right)\left(\left(1+m_{t}^{\omega}\right)^{\frac{1}{\omega}}-m_{t}\right)-\Delta E\left(T_{m}, m_{r e c}, c_{a m}\right)
$$

where $\Delta E$ is a function of $m_{r e c}, c_{a}, c_{a m}, T_{r e c}$ and $T_{m}$, and $u$ and $v$ are functions of $T_{r e c}$ only. Although a numerical solution of the whole equation system is possible, a numerical solution of equation (2.19) achieves identical results in a fraction of the computation time.

\subsection{Sensitivity analysis}

The sensitivity of computed $\Delta m$ was investigated with respect to the control variables $m_{r e c}, T_{m}, \Delta T=T_{r e c}-T_{m}$ (the reconstructed LGM temperature anomaly) and $c_{a} / c_{a m}$ (the ratio of palaeo to modern $\left[\mathrm{CO}_{2}\right]$ ). Here, sensitivity is represented by the partial derivatives of the computed $\Delta m$ with respect to each variable in turn, normalised as follows:

$$
S(x)=\frac{\operatorname{range}(x)}{\operatorname{range}(\Delta m)} \frac{\partial \Delta m}{\partial x}
$$

where $S(x)$ is the sensitivity of $\Delta m$ to the variable $x$ and $\operatorname{range}(\cdot)$ denotes the absolute difference between mean values for the modern data set and the LGM. 


\section{Results}

\subsection{Properties of the MI correction}

Fig.2 provides an example of the computed values of the correction term $\Delta m$ as a function of $m_{r e c}$ and $\Delta c_{a}$. Modern $\left[\mathrm{CO}_{2}\right]\left(c_{a m}\right)$ is taken to be $340 \mu \mathrm{mol} \mathrm{mol}^{-1}$ to reflect the fact that modern vegetation is not in equilibrium with the present, rapidly changing $\left[\mathrm{CO}_{2}\right]$. This value is close to that typically chosen as the baseline for process-based vegetation models (e.g. Haxeltine and Prentice, 1996). For illustration, Fig. 2 applies to a modern temperature of $20^{\circ} \mathrm{C}\left(T_{m}=20\right)$ and a reconstructed palaeotemperature of $15^{\circ} \mathrm{C}(\Delta T=-5)$. Colours are shown only for cases where $c_{i}>\Gamma^{*}$; in the left lower part of the rectangle, climate is too dry and $\left[\mathrm{CO}_{2}\right]$ too low for $\mathrm{C}_{3}$ photosynthesis. Some key points are immediately visible in Fig.2. At modern $\left[\mathrm{CO}_{2}\right]$ (represented by the right-hand edge of the graph), reconstructed MI should be corrected slightly downwards due to the reduced temperature. At low $\left[\mathrm{CO}_{2}\right]$ (the left-hand edge represents $170 \mu \mathrm{mol} \mathrm{mol}{ }^{-1}$ ), reconstructed MI requires substantial upward correction. The numerical values of the corrections generally increase with the absolute value of MI.

The sensitivity of the computed $\Delta m$ to different variables (Fig.3) carries a clear visual message, showing that $\left[\mathrm{CO}_{2}\right]$ - over the range by which it varies between glacial and interglacial climates - is by far the most important determinant of $\Delta m . \Delta m$ also becomes more sensitive to $m_{r e c}$ at low $\left[\mathrm{CO}_{2}\right]$. The sensitivities of $\Delta m$ to temperature are very small by comparison.

Figure 4 illustrates how leaf-internal $\mathrm{CO}_{2}\left(c_{i}\right)$ is influenced by ambient $\mathrm{CO}_{2}\left(c_{a}\right)$, moisture and temperature. The $\mathrm{CO}_{2}$ compensation point represents the point at which no net photosynthesis can take place in $\mathrm{C}_{3}$ plants. $\left(\mathrm{C}_{4}\right.$ plants can thrive below this point because of their possession of a leaf-internal $\mathrm{CO}_{2}$ concentrating mechanism). Note that this point increases quite steeply with temperature so that low temperatures to some extent mitigate the negative effect of low $\mathrm{CO}_{2}$ on $\mathrm{C}_{3}$ plants, while the advantage of $\mathrm{C}_{4}$ photosynthesis becomes decisive at high temperatures.

\subsection{Statistical reconstruction and the effect of the correction term}

The reconstructed LGM climate was on average $3^{\circ} \mathrm{C}$ cooler than today. The magnitude of the cooling varied, however, with sites in the continental interior showing changes of up to $10^{\circ} \mathrm{C}$ (e.g. Lake Frome, Ulungra Springs) while changes elsewhere were more muted (Figure 5; SI Table 6). Four sites in the southeastern part of the continent show temperatures $>2^{\circ} \mathrm{C}$ warmer than today. This apparently anomalous signal arises because there is a large shift at these sites from assemblages dominated by woody taxa under modern conditions to assemblages consisting of between $80-100 \%$ grasses and forbs at the LGM dataset. While the warming signal may be real, it could also reflect the absence of samples from cool/cold grasslands in the modern training set. The temperature reconstructions are broadly consistent with inferences about LGM climates in this region (Reeves et al., 2013). Pollen-based estimates suggest a cooling of $4^{\circ} \mathrm{C}$ in lowland Tasmania (Fletcher and Thomas, 2010); acid-racimisation of emu eggshell indicates a cooling of the order of $9^{\circ} \mathrm{C}$ in the continental interior (Miller et al., 1997). This gradient with greater cooling in the interior is also apparent in our reconstructions.

Although many sites register an increase in MI at the LGM compared to today, the reconstructed LGM climate was on average slightly drier than today $(-0.05)$. However, some sites in the southeastern part of the region and in the northeast show reductions in MI of $>0.8$ (Figure 5), implying a substantial shift towards more arid conditions (SI Table 6). These sites remain more arid than today after the $\mathrm{CO}_{2}$ correction is applied (Figure 5), but the anomalies are smaller and more consistent with the changes at other sites. Overall, the corrected reconstructions suggest that the climate was wetter than today at the LGM. The shift towards more open vegetation shown by pollen records at the LGM has generally been interpreted as indicating drier conditions (Harrison and Dodson, 1993; Pickett et al., 2004; Williams et al., 2009). However, geomorphic evidence from southeastern Australia indicates that lakes were high (Harrison and Dodson, 1993; Page et al., 1994; Bowler et al., 2012) and there was increased fluvial activity in the Riverine Plains and the Flinders Range (Page et al., 2009; Kemp and Rhodes, 2010; Haberlah et al., 2010) while speleothem records from South Australia indicate increased precipitation (Ayliffe et al., 1998). There is also geomorphic evidence for periodically wet conditions in northern Australia (Nott and Price, 1999; Reeves et al., 2007; Croke et al., 2010; Reeves et al., 2013). The discrepancy between the different lines of evidence has been interpreted as reflecting increased seasonality in precipitation (Kemp and Rhodes, 2010; Fitzsimmons et al., 2013) or an increase in runoff resulting from less water uptake by plants (Dosseto et al., 2010; Bowler et al., 2012). Our results suggest that the interpretation that the shift towards open vegetation is a direct reflection of increased aridity is simplistic.

As shown in Figure 6, the effect of the moisture index correction is a general uplift of the reconstructed MI values, amounting to a near-doubling at the lowest values of $m_{r e c}$ and an increase by as much as 1.5 units at the highest values of $m_{r e c}$. Adopting the corrected values of MI also has an important effect on the implied leaf-internal $\mathrm{CO}_{2}$. 
Without correction, estimated $c_{i}$ values are notably low both in absolute terms (at around 40 to $80 \mu \mathrm{mol} \mathrm{mol}^{-1}, c_{i}$ values are dangerously close to the compensation point in the upper range of reconstructed temperatures); and in relation to the LGM value of $c_{a}$ (implying $\chi \approx 0.2$ to 0.4 , which is substantially lower than normally encountered even under todays higher $c_{a}$ ). Correction of the MI elevates the values of $c_{i}$ to a more realistic range of 100 to 160 $\mu \mathrm{mol} \mathrm{mol}{ }^{-1}$ and $\chi \approx 0.5$ to 0.9 , similar to values seen in contemporary data (Wang et al., 2016).

\section{Discussion and Conclusion}

The analysis of global-scale patterns in ecophysiological quantities such as $\chi$ is a fast-developing field (see e.g. Wang et al., 2016). It seems likely that the method could be streamlined in various ways. It could also be extended to cover $\mathrm{C}_{4}$ photosynthesis, and to include palaeorecords of $\delta^{13} C$ in the analysis, for example. Nonetheless, the results provided here amount to a useful proof of concept. They show that a set of general equations can be used to make corrections of climatic moisture availability that take account of a major artefact in many current approaches to the reconstruction of past climates from data derived from plants. They also show that in order to consider ecophysiological effects it is not necessary to resort to numerical inversion of complex models with multiple PFTs. The analytical approach adopted here is considerably more transparent, as well as more general.

Nevertheless, the application of this approach to other regions of the world will require consideration of factors that are relatively unimportant and could therefore be neglected in the Australian case study presented here. Elevation, for example, has a direct impact on carbon assimilation because it affects the both the partial pressure of $\mathrm{O}_{2}$ (and thus the affinity of Rubisco for $\mathrm{CO}_{2}$ ) and the vapour pressure deficit (and hence the cost of water uptake). The relationship between elevation and $\chi$ is well-constrained by theory and empirical evidence (Wang et al., 2016) and this relationship could therefore be applied to sites at different elevation. It could also adjust for the very slight effect of the difference in elevation of individual sites between LGM and present day (ca $120 \mathrm{~m}$ ) caused by the lowering of sea level (Kageyama et al., 2016). In the Australian case study, it was possible to simplify the model inversion by only considering mean annual changes in climate. This simplification was based on the strong correlation between seasonal temperatures today (Herbert and Harrison, 2016) and the assumption that changes in temperature seasonality between the LGM and present would be small because of the strong maritime influence on Australian palaeoclimates. While the assumption of minimal changes in temperature seasonality is borne out by palaeoclimate simulations, this is not the case in the northern extratropics where the seasonal temperature range was $5-10^{\circ} \mathrm{C}$ greater than today (see e.g. Izumi et al., 2013, Figure 1). Changes of this magnitude could influence the seasonal cycle of moisture changes and thus would require a seasonally resolved treatment of carbon assimilation and water loss. Thus, while the methodology described here could be applied to other regions of the globe, it would require a series of other corrections to be made.

The specific application is encouraging, as it suggests a possible resolution of a long-standing puzzle regarding the LGM climate of southeastern Australia: namely, the apparent wetness of part of southeastern Australia at the LGM, based on physical (geomorphic) evidence for enhanced river runoff and high lake levels at a time when pollen-based reconstructions indicate aridity. Although a number of papers have dealt with the issue of $\left[\mathrm{CO}_{2}\right]$ effects at a global scale, and a number for Africa, to our knowledge these effects have not been considered before as a factor in the interpretation of regional Australian palaeoclimate records.

\section{Acknowledgements}

We thank Dr. Ines Hessler and Annika Herbert for assistance with the pollen data compilation, and Dr. Kev Willis for implementing the method of statistical climate reconstruction. We also thank Nancy Nichols for discussions of the limiting analyses and numerics. The work was supported by the Australian Research Council, grant number DP1201100343 (SPH). It is a contribution to the AXA Chair Programme in Biosphere and Climate Impacts and the Imperial College initiative on Grand Challenges in Ecosystems and the Environment (ICP). Sean Cleator was supported by a UK Natural Environment Research Programme (NERC) scholarship as part of the SCENARIO Doctoral Training Partnership.

\section{Appendices}

\section{A. Model Inversion}

The model can be solved for $m_{t}$ numerically by solving equation (2.16); however, this set of governing equations can be simplified by solving for $\Delta E$ independent of $m_{t}$. 
We first take

$$
s=\frac{g_{0} c_{a} e\left(T_{m}, m_{r e c}, c_{a_{m}}\right)}{1.6}
$$

and

$$
t=\frac{1}{C}\left(\frac{K}{\eta}\right)^{\frac{1}{2}}
$$

and so we can write equation (2.16) as

$$
\Delta E \cdot\left(t \Delta E^{-\frac{1}{4}}+1\right)=t \Delta E^{\frac{3}{4}}+\Delta E=s .
$$

We binomially expand to a quartic in $\Delta E$ in the form of

$$
\Delta E^{4}+\left(-4 s-t^{4}\right) \Delta E^{3}+6 s^{2} \Delta E^{2}+\left(-4 s^{3}\right) \Delta E+s^{4}=0 .
$$

The root of (A.4) can be found using a quartic formula or solver.

We can then use equation (2.6) with the $\Delta E$ as the solution of equation (A.4) to write

$$
\Delta E(s, t)=\left(u e^{-0.74 m}+v\right)\left(\left(1+m_{t}^{\omega}\right)^{\frac{1}{\omega}}-m_{t}\right)
$$

where

$$
u=0.6611\left(0.83 R_{0} 0.5-\left(107-T_{\text {rec }}\right) 0.8\right) \tau
$$

and

$$
v=\left(0.83 R_{0} 0.25-\left(107-T_{\text {rec }}\right) 0.2+0.2175\left(0.83 R_{0} 0.5-\left(107-T_{\text {rec }}\right) 0.8\right)\right) \tau .
$$

with

$$
\tau=\frac{1}{\lambda}\left(1+\frac{\gamma\left(c+T_{r e c}\right)^{2}}{a b c} \exp \left[-\frac{b T_{r e c}}{c+T_{r e c}}\right]\right)^{-1} .
$$

Equation (A.5) is then posed as a minimisation problem

$$
F\left(m_{t}\right)=\left(u e^{-0.74 m}+v\right)\left(\left(1+m_{t}^{\omega}\right)^{\frac{1}{\omega}}-m_{t}\right)-\Delta E(s, t)
$$

where we use the fortran MINPACK solver to find the $m_{t}$ which minimises $F$. Since $\Delta E(s, t), u, v$ and $\tau$ don't depend on $m_{t}$ they can be pre calculated and so the solver need only solve equation (A.5). Making this simplification is computationally cheaper and gives the same results compared to solving equation (2.19).

\section{References}

Ainsworth, E. A., Rogers, A., 2007. The response of photosynthesis and stomatal conductance to rising $\left[\mathrm{CO}_{2}\right]$ : mechanisms and environmental interactions. Plant, Cell \& Environment 30, 258-270.

Allen, R. G., Pereira, L. S., Raes, D., Smith, M., 1998. Crop evapotranspiration - guidelines for computing crop water requirements - FAO irrigation and drainage paper 56. FAO, Rome 300, D05109.

Ayliffe, L., Marianelli, P., Moriarty, K., Wells, R., McCulloch, M., Mortimer, G., Hellstrom, J., 1998. 500 ka precipitation record from southeastern Australia: evidence for interglacial relative aridity. Geology, 147-150.

Bartlein, P. J., Harrison, S. P., Brewer, S., Connor, S., Davis, B. A. S., Gajewski, K., Guiot, J., Harrison-Prentice, T. I., Henderson, A., Peyron, O., Prentice, I. C., Scholze, M., Seppä, H., Shuman, B., Sugita, S., Thompson, R. S., Viau, A. E., Williams, J., Wu, H., 2011. Pollen-based continental climate reconstructions at 6 and 21 ka: a global synthesis. Climate Dynamics 37, 775-802.

Bernacchi, C., Singsaas, E., Pimentel, C., Portis Jr, A., Long, S., 2001. Improved temperature response functions for models of Rubisco-limited photosynthesis. Plant, Cell \& Environment 24, 253-259.

Bond, W., Midgley, G., Woodward, F., 2003. The importance of low atmospheric $\mathrm{CO}_{2}$ and fire in promoting the spread of grasslands and savannas. Global Change Biology 9, 973-982.

Bowler, J. M., Gillespie, R., Johnston, H., Boljkovac, K., 2012. Wind v water: Glacial maximum records from Willandra lakes. Terra Australia 34, 271-296. 
Bragg, F. J., Prentice, I. C., Harrison, S. P., Eglinton, G., Foster, P. N., Rommerskirchen, F., Rullkötter, J., 2013. Stable isotope and modelling evidence for $\mathrm{CO}_{2}$ as a driver of glacial-interglacial vegetation shifts in southern Africa. Biogeosciences 10, 2001-2010.

Cowling, S. A., Shin, Y., 2006. Simulated ecosystem threshold responses to co-varying temperature, precipitation and atmospheric $\mathrm{CO}_{2}$ within a region of Amazonia. Global Ecology and Biogeography 15, 553-566.

Cowling, S. A., Sykes, M. T., 1999. Physiological significance of low atmospheric $\mathrm{CO}_{2}$ for plant-climate interactions. Quaternary Research 52, 237-242.

Croke, J., Jansen, J., Amos, K., Pietsch, T., 2010. A 100 ka record of fluvial activity in the Fitzroy river basin, tropical northeastern Australia. Quaternary Science Reviews 30, 1681-1695.

Dekker, S. C., Groenendijk, M., Booth, B. B. B., Huntingford, C., Cox, P. M., 2016. Spatial and temporal variations in plant water use efficiency inferred from tree-ring, eddy covariance and atmospheric observations. Earth System Dynamics 7, 525-533.

Dewar, R. C., 1997. A simple model of light and water use evaluated for Pinus radiata. Tree Physiology 17, 259-265.

Donohue, R. J., Roderick, M. L., McVicar, T. R., Farquhar, G. D., 2013. Impact of $\mathrm{CO}_{2}$ fertilization on maximum foliage cover across the globe's warm, arid environments. Geophysical Research Letters 40, 3031-3035.

Dosseto, A., Hesse, P., Maher, K., Fryirs, K., Turner, S., 2010. Climatic and vegetation control on sediment dynamics during the last glacial cycle. Geology 38, 395-398.

Farquhar, G. D., 1997. Carbon dioxide and vegetation. Science 278, 1411.

Farquhar, G. D., von Caemmerer, S., Berry, J. A., 1980. A biochemical model of photosynthetic $\mathrm{CO}_{2}$ assimilation in leaves of $\mathrm{C}_{3}$ species. Planta 149, 78-90.

Fitzsimmons, K., Cohen, T., Hesse, P., Jansen, J., Nanson, G., May, J.-H., Barrows, T., Haberlah, D., Hilgers, A., Kelly, T., Larsen, J., Lomax, J., Treble, P., 2013. Late Quaternary palaeoenvironmental change in the Australian drylands. Quaternary Science Reviews 74, 78-96.

Fletcher, M.-S., Thomas, I., 2010. A quantitative late Quaternary temperature reconstruction from western Tasmania, Australia. Quaternary Science Reviews 29, 2351-2361.

Gerhart, L. M., Harris, J. M., Nippert, J. B., Sandquist, D. R., Ward, J. K., 2012. Glacial trees from the La Brea tar pits show physiological constraints of low $\mathrm{CO}_{2}$. New Phytologist 194, 63-69.

Gerhart, L. M., Ward, J. K., 2010. Plant responses to low $\left[\mathrm{CO}_{2}\right]$ of the past. New Phytologist 188, 674-695.

Guiot, J., Torre, F., Jolly, D., Peyron, O., Boreux, J. J., Cheddadi, R., 2000. Inverse vegetation modeling by Monte Carlo sampling to reconstruct palaeoclimates under changed precipitation seasonality and $\mathrm{CO}_{2}$ conditions: application to glacial climate in Mediterranean region. Ecological Modelling 127, 119-140.

Haberlah, D., Williams, M., Halverson, G., Mctainsh, G., Hill, S., Hrstka, T., Jaime, P., Butcher, A., Glasby, P., 2010. Loess and floods: high-resolution multiproxdata of Last Glacial Maximum (LGM) slackwater deposition in the Flinders Ranges, semi-arid South Australia. Quaternary Science Reviews 29, 2673-2693.

Harrison, S., Dodson, J., 1993. Climates of Australia and New Guinea since 18,000 yr B.P. In Global Climates since the Last Glacial Maximum (H.E. Wright, Jr, J.E. Kutzbach, T. Webb III, W.F. Ruddiman, F.A. Street-Perrott, and P.J. Bartlein, eds). University of Minnesota Press, Minneapolis, 265-293.

Harrison, S. P., Prentice, I. C., 2003. Climate and $\mathrm{CO}_{2}$ controls on global vegetation distribution at the Last Glacial Maximum: analysis based on palaeovegetation data, biome modelling and palaeoclimate simulations. Global Change Biology 9, 983-1004.

Haxeltine, A., Prentice, I. C., 1996. BIOME3: An equilibrium terrestrial biosphere model based on ecophysiological constraints, resource availability, and competition among plant functional types. Global Biogeochemical Cycles 10, 693-709.

Herbert, A. V., Harrison, S. P., 2016. Evaluation of a modern-analogue methodology for reconstructing Australian palaeoclimate from pollen. Review of Palaeobotany and Palynology 226, 65-77. 
Huang, Y., Street-Perrott, F. A., Metcalfe, S. E., Brenner, M., Moreland, M., Freeman, K., 2001. Climate change as the dominant control on glacial-interglacial variations in $\mathrm{C}_{3}$ and $\mathrm{C}_{4}$ plant abundance. Science 293, 1647-1651.

Huntingford, C., Monteith, J., 1998. The behaviour of a mixed-layer model of the convective boundary layer coupled to a big leaf model of surface energy partitioning. Boundary-Layer Meteorology 88, 87-101.

Hutchinson, M. F., 2004. ANUSPLIN Version 4.3. Centre for Resource and Environmental Studies. The Australian National University, Canberra, ACT.

Izumi, K., Bartlein, P., Harrison, S., 2013. Consistent behaviour of the climate system in response to past and future forcing. Geophysical Research Letters 40, 1817-1823.

Jolly, D., Haxeltine, A., 1997. Effect of low glacial atmospheric $\mathrm{CO}_{2}$ on tropical African montane vegetation. Science $276,786-788$.

Kageyama, M., Braconnot, P., Harrison, S. P., Haywood, A. M., Jungclaus, J., Otto-Bliesner, B. L., Peterschmitt, J.-Y., Abe-Ouchi, A., Albani, S., Bartlein, P. J., et al., 2016. PMIP4-CMIP6: the contribution of the Paleoclimate Modelling Intercomparison Project to CMIP6. Geoscientific Model Development Discussions.

Keenan, T. F., Hollinger, D. Y., Bohrer, G., Dragoni, D., Munger, J. W., Schmid, H. P., Richardson, A. D., 2013. Increase in forest water-use efficiency as atmospheric carbon dioxide concentrations rise. Nature 499, 324-327.

Kemp, J., Rhodes, E., 2010. Episodic fluvial activity of inland rivers in southeastern Australia: Palaeochannel systems and terraces of the Lachlan River. Quaternary Science Reviews 29, 732-752.

Kgope, B. S., Bond, W. J., Midgley, G. F., 2010. Growth responses of African savanna trees implicate atmospheric $\left[\mathrm{CO}_{2}\right]$ as a driver of past and current changes in savanna tree cover. Austral Ecology 35, 451-463.

Linacre, E., 1968. Estimating the net-radiation flux. Agricultural Meteorology 5, 49-63.

Martin Calvo, M., Prentice, I. C., 2015. Effects of fire and $\mathrm{CO}_{2}$ on biogeography and primary production in glacial and modern climates. New Phytologist 208, 987-994.

Miller, G., Magee, J., Jull, A., 1997. Low-latitude glacial cooling in the Southern Hemisphere from amino-acid racemisation in emu eggshells. Nature 385, 241-244.

Monteith, J., 1995. Accommodation between transpiring vegetation and the convective boundary layer. Journal of Hydrology 166, 251-263.

Nott, J., Price, D., 1999. Waterfalls, floods and climate change: evidence from tropical Australia. Earth and Planetary Science Letters 171, 267-276.

Page, K., Dare-Edwards, A., Nanson, G., Price, D., 1994. Late Quaternary evolution of Lake Urana, New South Wales, Australia. Journal of Quaternary Science 9, 47-57.

Page, K. J., Kemp, J., Nanson, G., 2009. Late Quaternary evolution of riverine plain paleochannels, southeastern Australia. Australian Journal of Earth Sciences 56, 19-33.

Pickett, E. J., Harrison, S. P., Hope, G., Harle, K., Dodson, J. R., Kershaw, A. P., Prentice, I. C., Backhouse, J., Colhoun, E. A., D'Costa, D., Flenley, J., Grindrod, J., Haberle, S., Hassell, C., Kenyon, C., Macphail, M., Martin, A. H., McKenzie, M., Newsome, J. C., Penny, D., Powell, J., Raine, J. I., Southern, W., Stevenson, J., Sutra, J. P., Thomas, I., van der Kaars, S., Ward, J., 2004. Pollen-based reconstructions of biome distributions for Australia, Southeast Asia and the Pacific (SEAPAC region) at 0, 6000 and 18,000 14C yr BP. Journal of Biogeography 31, 1381-1444.

Prentice, I. C., Dong, N., Gleason, S. M., Maire, V., Wright, I. J., 2014. Balancing the costs of carbon gain and water transport: testing a new theoretical framework for plant functional ecology. Ecology Letters 17, 82-91.

Prentice, I. C., Harrison, S. P., 2009. Ecosystem effects of $\mathrm{CO}_{2}$ concentration: evidence from past climates. Climate of the Past 5 (3), 297-307.

Ramstein, G., Kageyama, M., Guiot, J., Wu, H., Hély, C., Krinner, G., Brewer, S., 2007. How cold was Europe at the Last Glacial Maximum? A synthesis of the progress achieved since the first PMIP model-data comparison. Climate of the Past 3, 331-339. 
Reeves, J., Chivas, A., Garcia, A., De Deckker, P., 2007. Palaeoenvironmental change in the Gulf of Carpentaria (Australia) since the last interglacial based on Ostracoda. Palaeogeography, Palaeoclimatology, Palaeoecology $246,163-187$.

Reeves, J. M., Barrows, T. T., Cohen, T. J., Kiem, A. S., Bostock, H. C., Fitzsimmons, K. E., Jansen, J. D., Kemp, J., Krause, C., Petherick, L., Phipps, S. J., 2013. Climate variability over the last 35,000 years recorded in marine and terrestrial archives in the Australian region: an OZ-INTIMATE compilation. Quaternary Science Reviews $74,21-34$.

Ukkola, A. M., Prentice, I. C., Keenan, T. F., van Dijk, A. I., Viney, N. R., Myneni, R. B., Bi, J., 2015. Reduced streamflow in water-stressed climates consistent with $\mathrm{CO}_{2}$ effects on vegetation. Nature Climate Change 6, 75-78.

Vogel, H., 1921. Das temperaturabhängigkeitsgesetz der viskosität von flüssigkeiten. Physikalische Zeitschrift 22, 645-646.

Wang, H., Prentice, I., Davis, T., 2014. Biophysical constraints on gross primary production by the terrestrial biosphere. Biogeoscience 11, 5987-6001.

Wang, H., Prentice, I., Ni, J., 2013. Data-based modelling and environmental sensitivity of vegetation in China. Biogeosciences 10, 5817-5830.

Wang, H., Prentice, I. C., Cornwell, W., Keenan, T., Davis, T., Wright, I., Evans, B., Peng, C., 2016. A universal model for carbon dioxide uptake by plants. bioRxiv, Preprint.

Ward, J. K., Harris, J. M., Cerling, T. E., Wiedenhoeft, A., Lott, M. J., Dearing, M.-D., Coltrain, J. B., Ehleringer, J. R., 2005. Carbon starvation in glacial trees recovered from the La Brea tar pits, southern California. Proceedings of the National Academy of Sciences of the United States of America 102, 690-694.

Williams, M., Cook, E., van der Kaars, S., Barrows, T., Shulmeister, J., Kershaw, P., 2009. Glacial and deglacial climatic patterns in Australia and surrounding regions from 35000 to 10000 years age reconstructed from terrestrial and nearshore proxy data. Quaternary Science Reviews 28, 2398-2419.

Wu, H., Guiot, J., Brewer, S., Guo, Z., 2007. Climatic changes in Eurasia and Africa at the Last Glacial Maximum and mid-Holocene: reconstruction from pollen data using inverse vegetation modelling. Climate Dynamics 29, $211-229$.

Zhang, L., Hickel, K., Dawes, W., Chiew, F. H., Western, A., Briggs, P., 2004. A rational function approach for estimating mean annual evapotranspiration. Water Resources Research 40. 
Figures

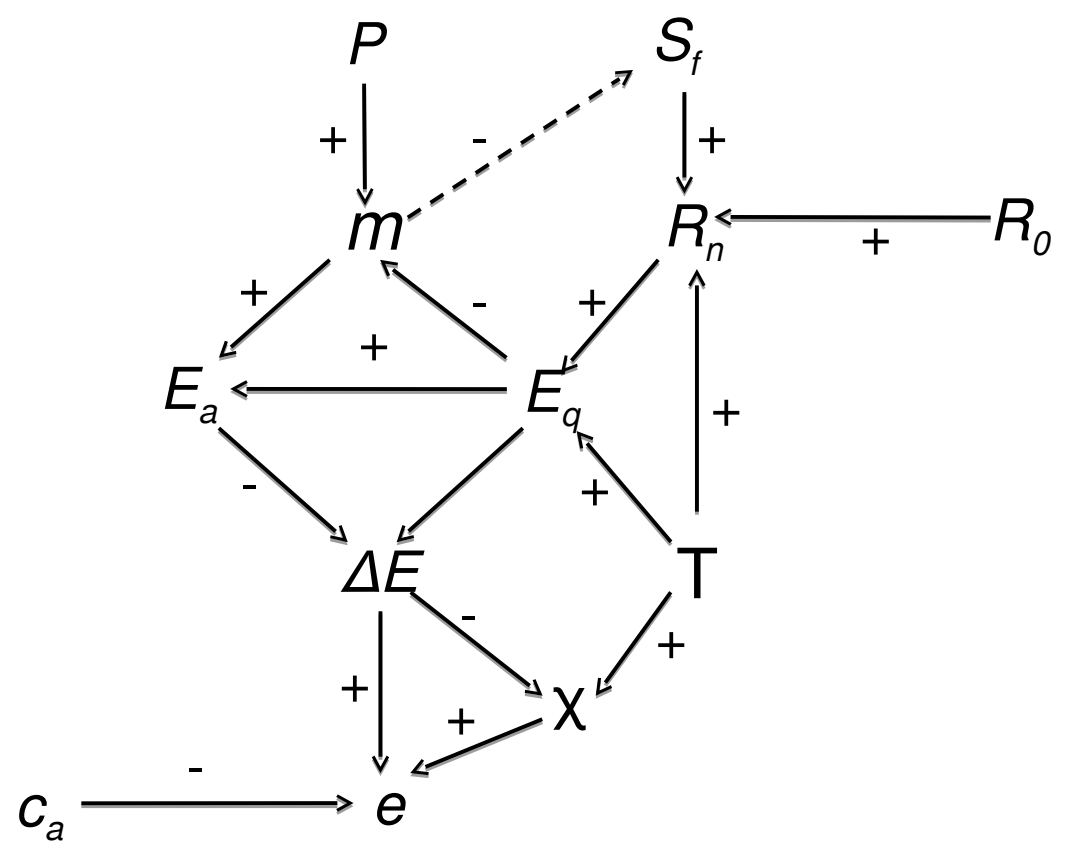

Figure 1: Environmental influences on water lost per unit carbon gained $(e)$, the inverse of water use efficiency, for $\mathrm{C}_{3}$ photosynthesis. Symbols: $P$ precipitation, $S_{f}$ sunshine fraction, $\mathrm{m}$ moisture index or MI $\left(=P / E_{q}\right), R_{n}$ net radiation, $R_{0}$ insolation, $E_{a}$ actual evapotranspiration, $E_{q}$ equilibrium evapotranspiration, $\Delta E$ atmospheric water deficit $\left(=E_{q}-E_{a}\right), \chi$ ratio of leaf-internal $\left(c_{i}\right)$ to ambient $\left(c_{a}\right)\left[\mathrm{CO}_{2}\right]$. 


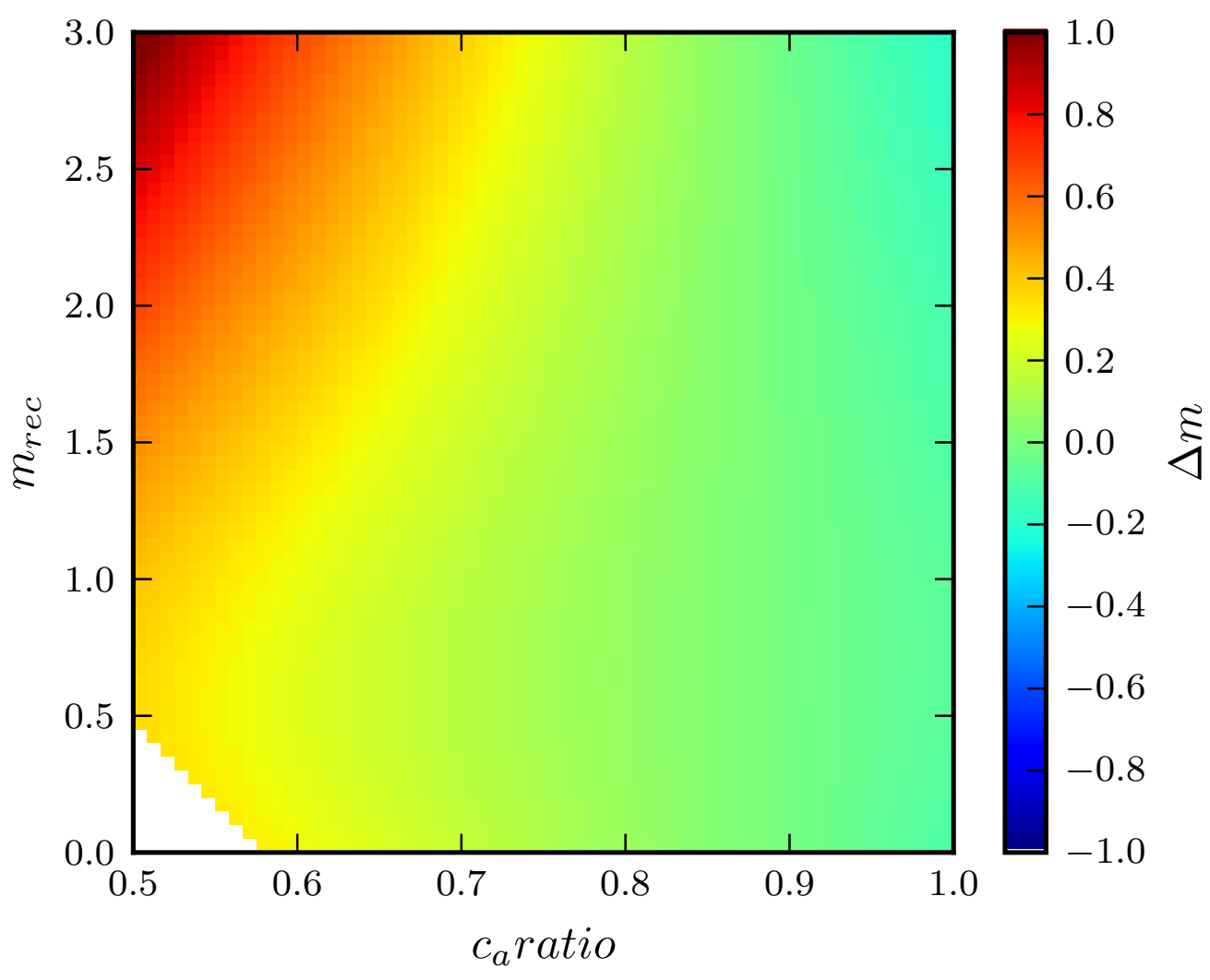

Figure 2: The computed MI correction term $(\Delta m)$ as a function of the reconstructed MI value $\left(m_{\text {rec }}\right)$ and the ratio of past to modern $\mathrm{CO}_{2}\left(\Delta c_{a}\right)$, for a modern annual mean temperature of $20^{\circ} \mathrm{C}$ and a cooling (relative to modern) by $5^{\circ} \mathrm{C}$. The white area lies below the $\left[\mathrm{CO}_{2}\right]$ compensation point. 

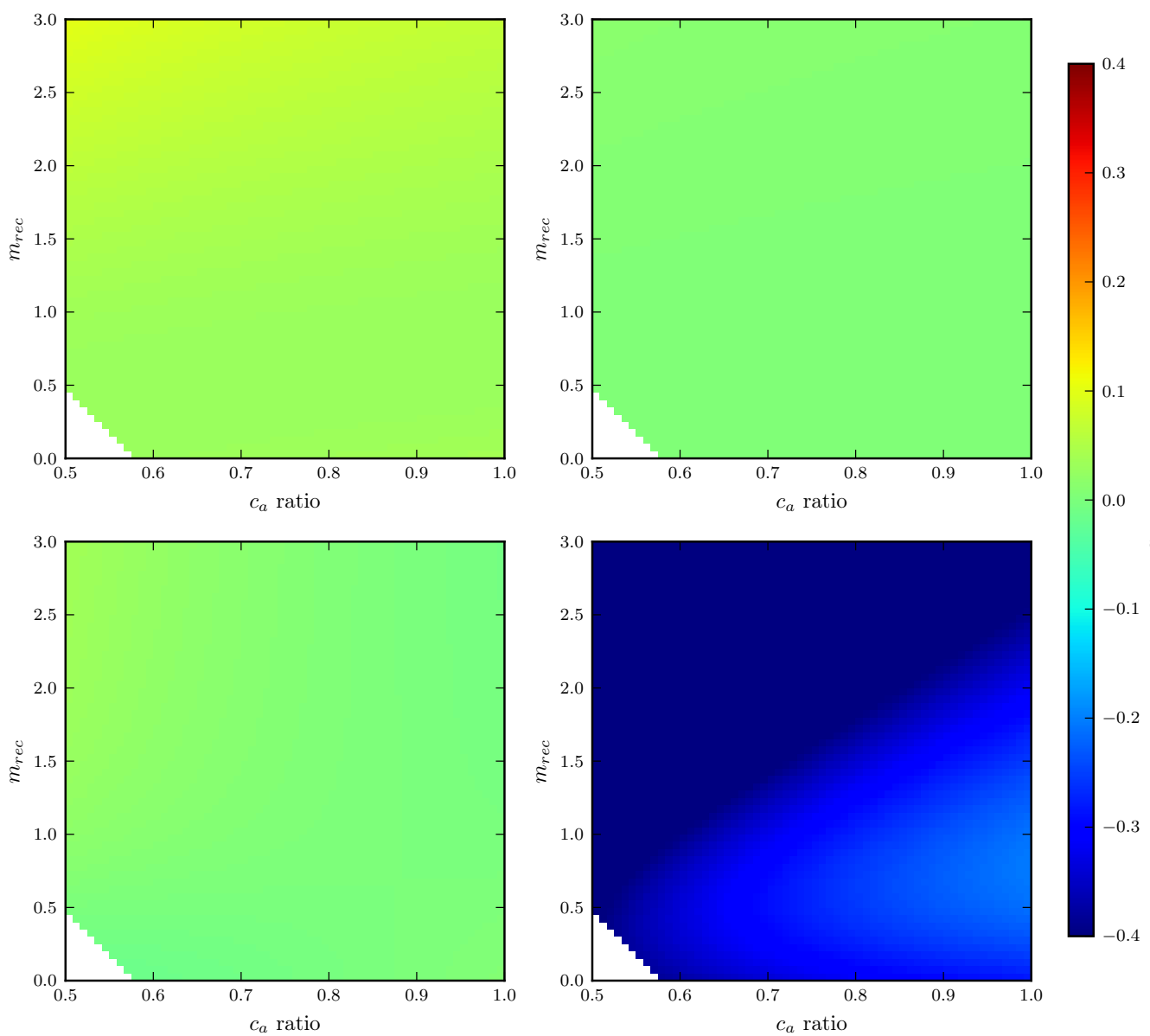

Figure 3: Plots showing the sensitivity of the change in MI $(\Delta m)$ to uncertainties in the input following equation (2.20). Top left shows the sensitivity of $\Delta m$ to $\Delta T$, top right $T_{r e c}$, bottom left $m_{r e c}$ and bottom right $c_{a} / c_{a m}$, for the range of values of $m_{r e c}$ and $c_{a}$ ratio plotted at a modern annual mean temperature of $20^{\circ} \mathrm{C}$ and a cooling (relative to modern) by $5^{\circ} \mathrm{C}$. Figure 9 shows these sensitivities with varying mean annual temperature and LGM cooling. 


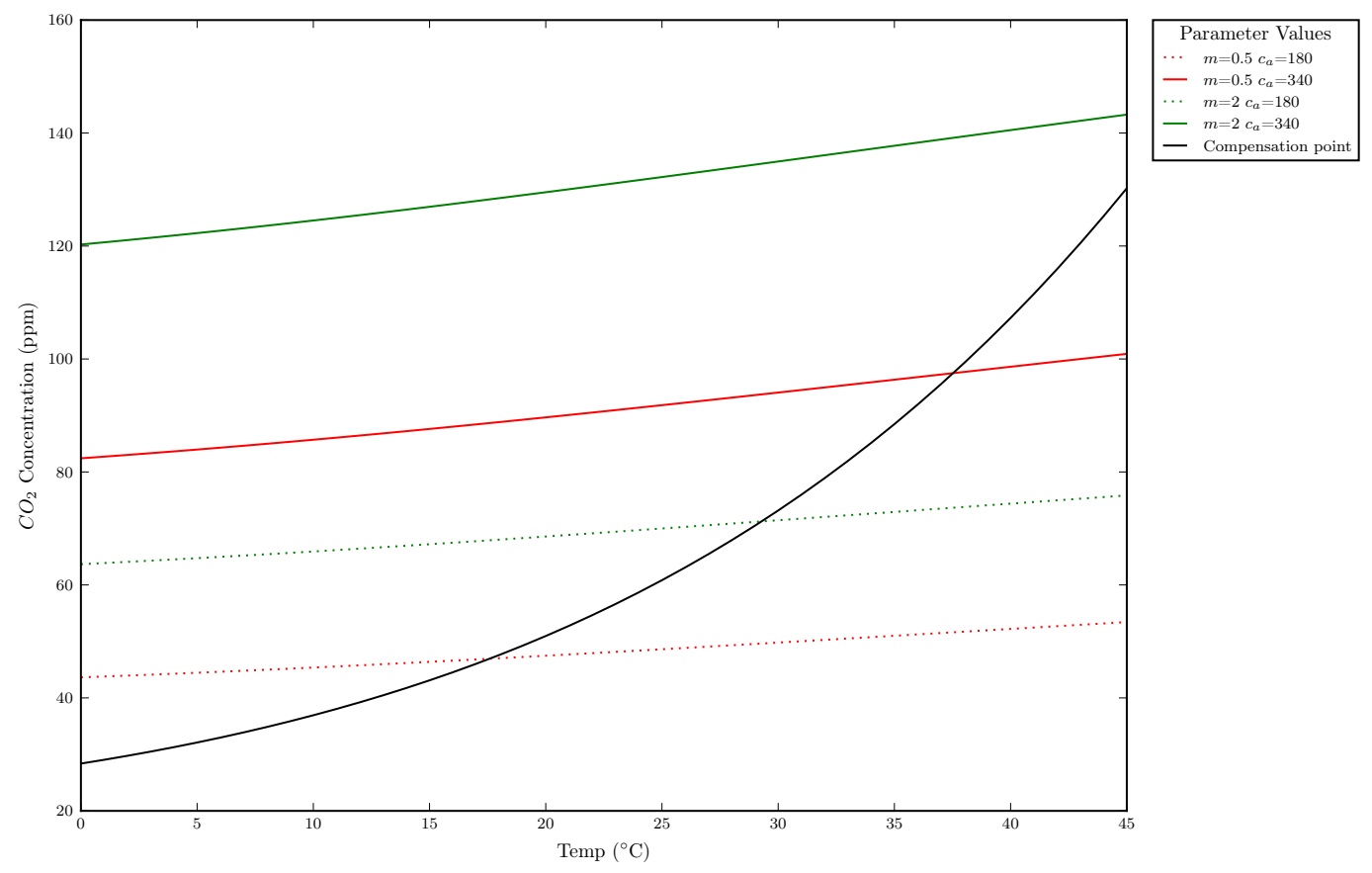

Figure 4: The black line represents the compensation point. The coloured lines represent the leaf internal $\mathrm{CO}_{2}$ for various combinations of atmospheric $\mathrm{CO}_{2}$ and moisture index. These are then plotted against temperature, hence all parts of the coloured line above the black line are above the compensation point and all parts below the line are below the compensation point. 

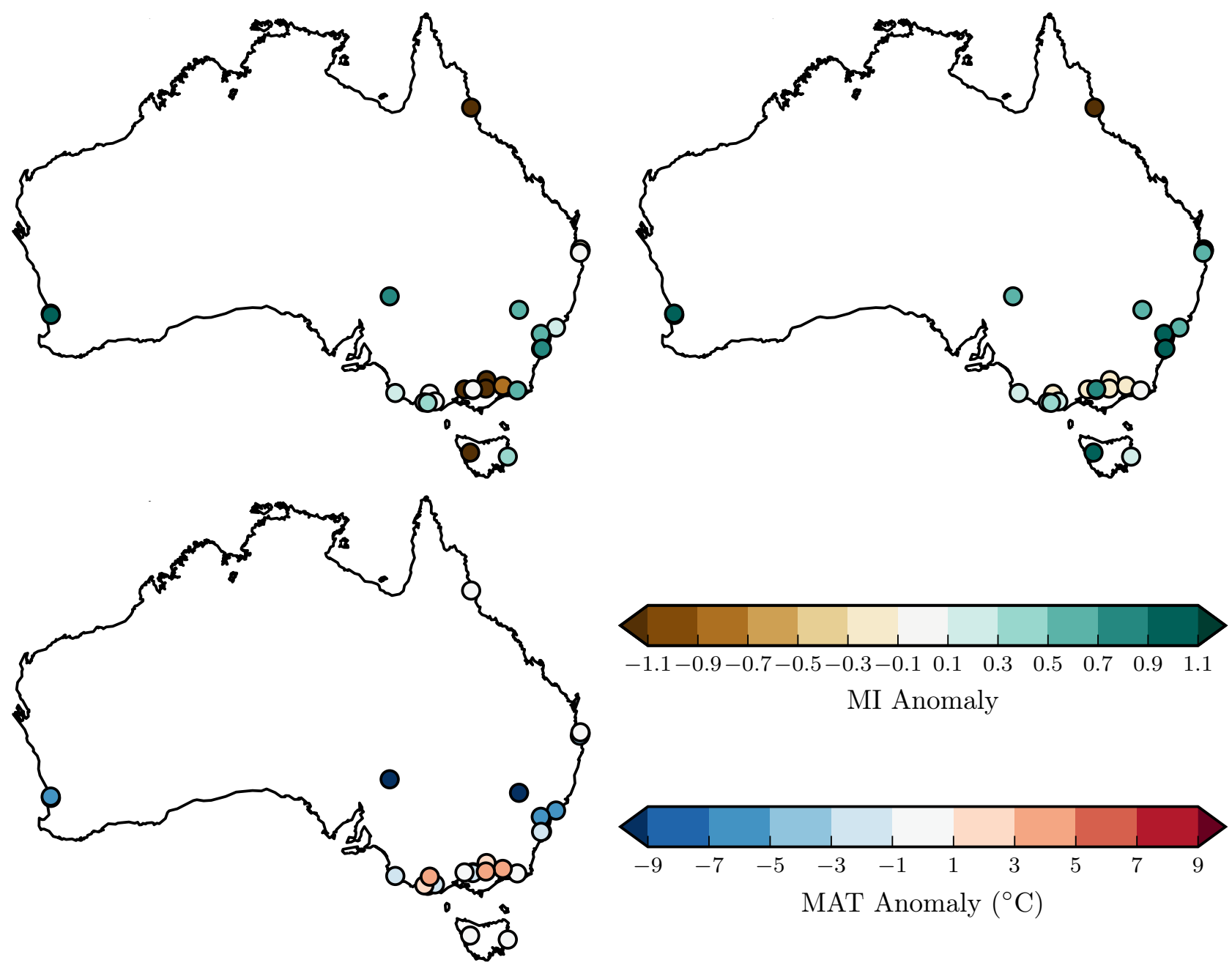

Figure 5: The anomaly of MAT (bottom left), uncorrected moisture index (top left) and corrected moisture index (top right) for all the sites sampled in the data set plotted against their location. The samples from the same site are averaged together. 


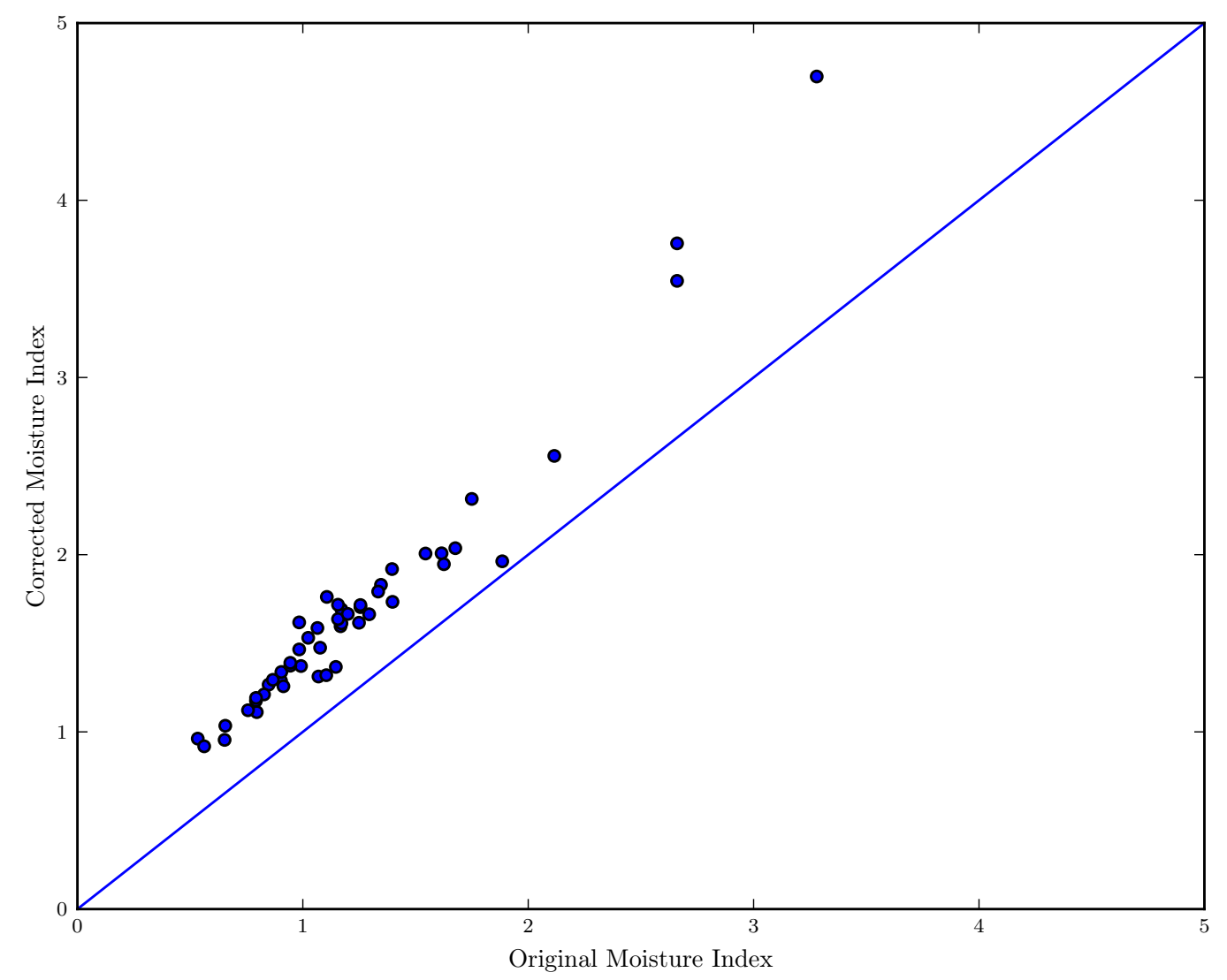

Figure 6: The change in moisture index generated by the model. The blue line is the $1: 1$ line. 


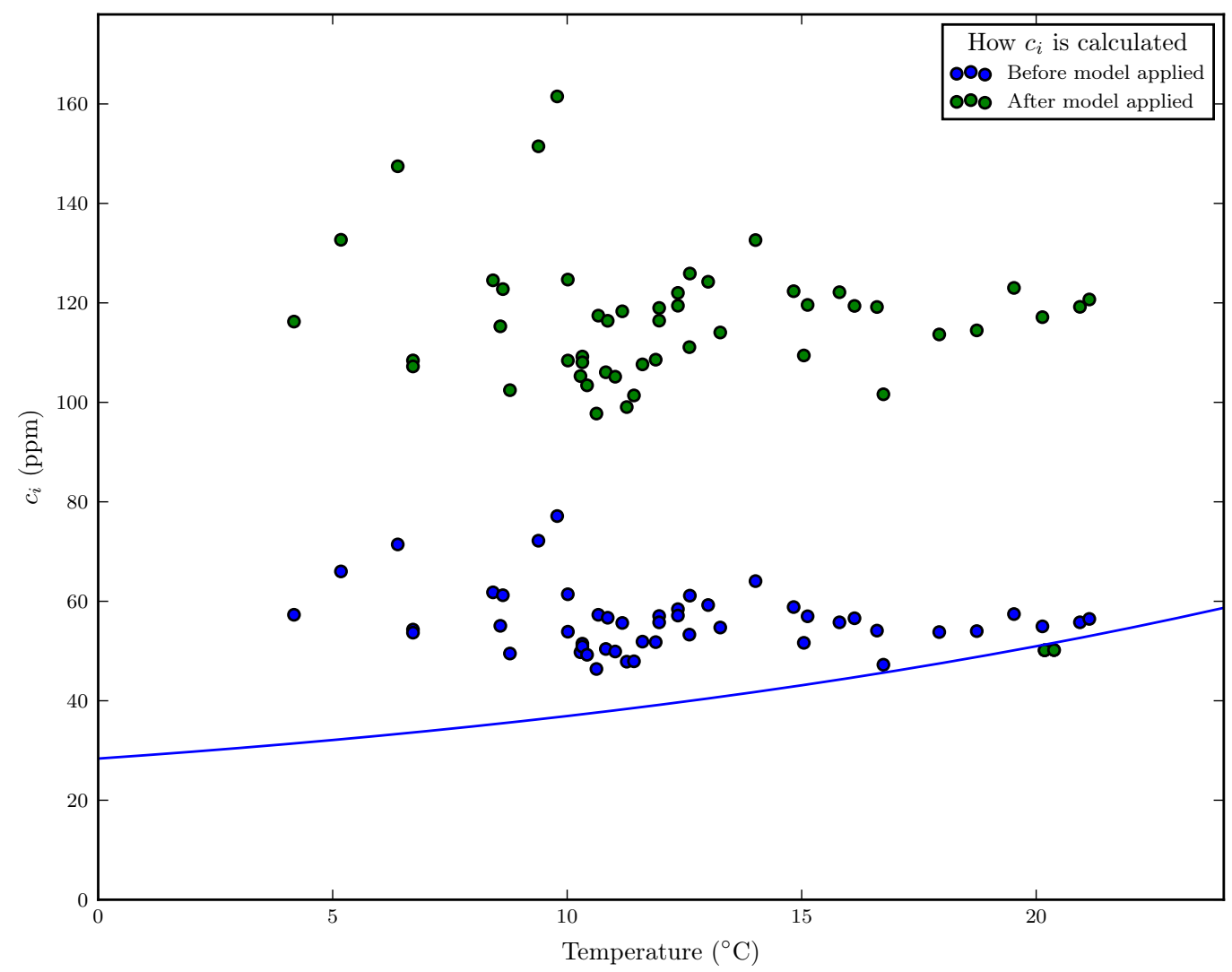

Figure 7: The blue line is the compensation point as in figure 4. The dots represent the calculated plant internal $\mathrm{CO}_{2}$ from a specific site, before and after the application of the correction term $\Delta m$.

Figure 8: An animation showing the same as figure 2 for different values of modern annual mean temperature $\left(T_{r e f}\right)$ and cooling relative to the modern $(\Delta T)$.

Figure 9: An animation showing the same as figure 3 for different values of modern annual mean temperature $\left(T_{r e f}\right)$ and cooling relative to the modern $(\Delta T)$. 


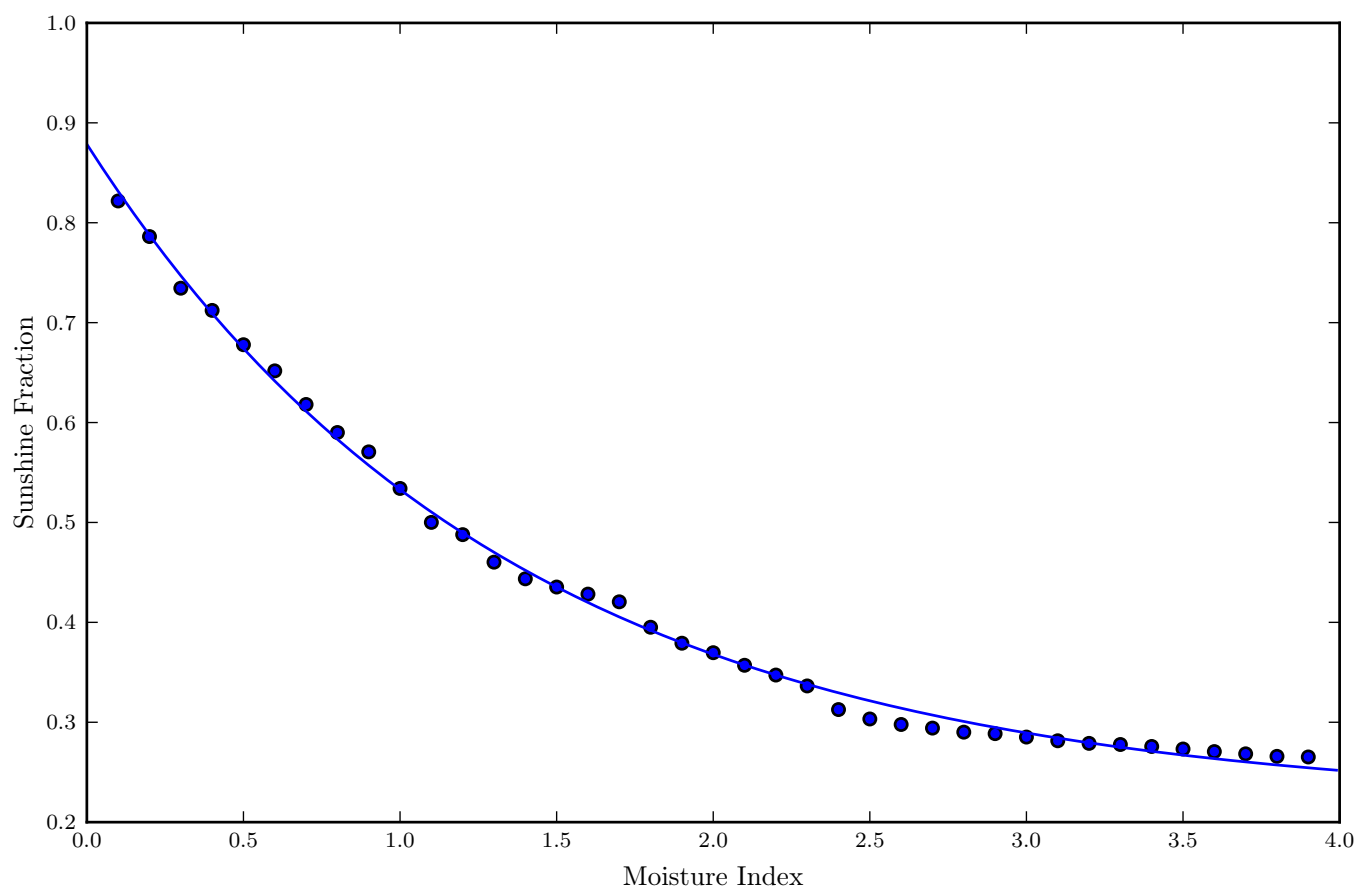

Figure 10: The strong empirical relationship between the sunshine fraction $\left(S_{f}\right)$ and moisture index $(m)$. The blue dots show the average sunshine fraction for a particular moisture index that has been rounded to 1 decimal place. These are data points from Australia in the interval of 1970 - 1999 (M. Hutchinson, pers.comm.). The blue line shows equation (2.5), the curve found through applying non-linear regression to the data points. 


\title{
Supplementary Information: Reconstructing ice-age palaeoclimates: quantifying low- $\mathrm{CO}_{2}$ effects on plants
}

\author{
Prentice, I.C. ${ }^{\mathrm{a}, \mathrm{b}}$, Cleator, S.F. ${ }^{\mathrm{c}}$, Huang, Y.H.c ${ }^{\mathrm{c}}$, Harrison, S.P. ${ }^{\mathrm{b}, \mathrm{d}}$, Roulstone, I. ${ }^{\mathrm{c}}$ \\ ${ }^{a}$ AXA Chair of Biosphere and Climate Impacts, Department of Life Sciences, Imperial College London, Silwood Park Campus, \\ Buckhurst Road, Ascot SL5 7PY, UK \\ ${ }^{b}$ Department of Biological Sciences, Macquarie University, North Ryde, NSW 2109, Australia \\ ${ }^{c}$ Department of Mathematics, University of Surrey, Guildford GU2 7XH, UK \\ ${ }^{d}$ School of Archaeology, Geography and Environmental Sciences (SAGES), University of Reading, Whiteknights, Reading RG6 6AH, \\ $U K$ \\ Corresponding author: Iain Colin Prentice \\ AXA Chair of Biosphere and Climate Impacts, Department of Life Sciences \\ Imperial College London, Silwood Park Campus, Buckhurst Road \\ Ascot SL5 7PY, UK \\ iain.colin.prentice@gmail.com
}


This SI contains information on the modern (SI Table 1) and fossil (SI Table 2) pollen data used for reconstructions, the definition of the plant functional types (PFTs) used (SI Table 3) and details of the allocation of individual pollen taxa to these PFTs (SI Table 4). The weightings used to allocate ambiguous to taxa to PFTs are given in SI Table 5. SI Table 6 gives the modern and Last Glacial Maximum (LGM) reconstructions at each of the LGM sites.

Table 1: Modern pollen samples used for the test the climate reconstruction method. The table gives the names of the site (site name) and of the core (entity name), the latitude and longitude of the core location (in decimal degrees) and the elevation, the sample number and the estimated age of the sample (in calendar years before present (yr BP). Present is conventionally defined as $1950 \mathrm{CE}$, so negative ages represent years post-1950 CE.

Table 2: Pollen samples used for the reconstructions of Last Glacial Maximum (LGM) climates. The table gives the names of the site (site name) and of the core (entity name), the latitude and longitude of the core location (in decimal degrees) and the elevation, the sample number and the estimated age of the sample (in calendar years before present, yr BP).

Table 3: Definition of plant functional types (PFTs) used in the statistical reconstructions, and the codes used for each PFT.

Table 4: Allocation of pollen taxa to plant functional types (PFTs). The codes for the PFTs are given in SI Table 3 .

Table 5: Relative weightings for cold tolerance $\left(V_{T}\right)$ and the degree of openness of the vegetation $\left(V_{C}\right)$ for different plants functional types (PFTs) recognized in Australia. The ranges go from a minimum of 1 (cold tolerant, open vegetation) to a maximum of 4 (cold intolerant, closed vegetation). No attempt is made to classify PFTs that have no obvious cold-temperature limit (eurythermic plants) and these are shown as n/a.

Table 6: Modern and Last Glacial Maximum (LGM) reconstructions of mean annual temperature (MAT, ${ }^{\circ} \mathrm{C}$ ) and moisture index (MI, unitless) for each of the LGM samples. The latitude and longitude of the site, and of the grid cell used for the derivation of the modern climate data are given in decimal degrees. The modern observed MAT is $T_{m}$, the reconstructed LGM MAT is $T_{r e c}$ and the reconstructed LGM MI is $M_{r e c}$. The estimated age of each LGM sample (in calendar years before present, yr BP) is also given. The change in MAT and MI between LGM and present-day is given in the final columns. 